\title{
Acute rheumatic fever and exposure to poor housing conditions in New Zealand: A descriptive study
}

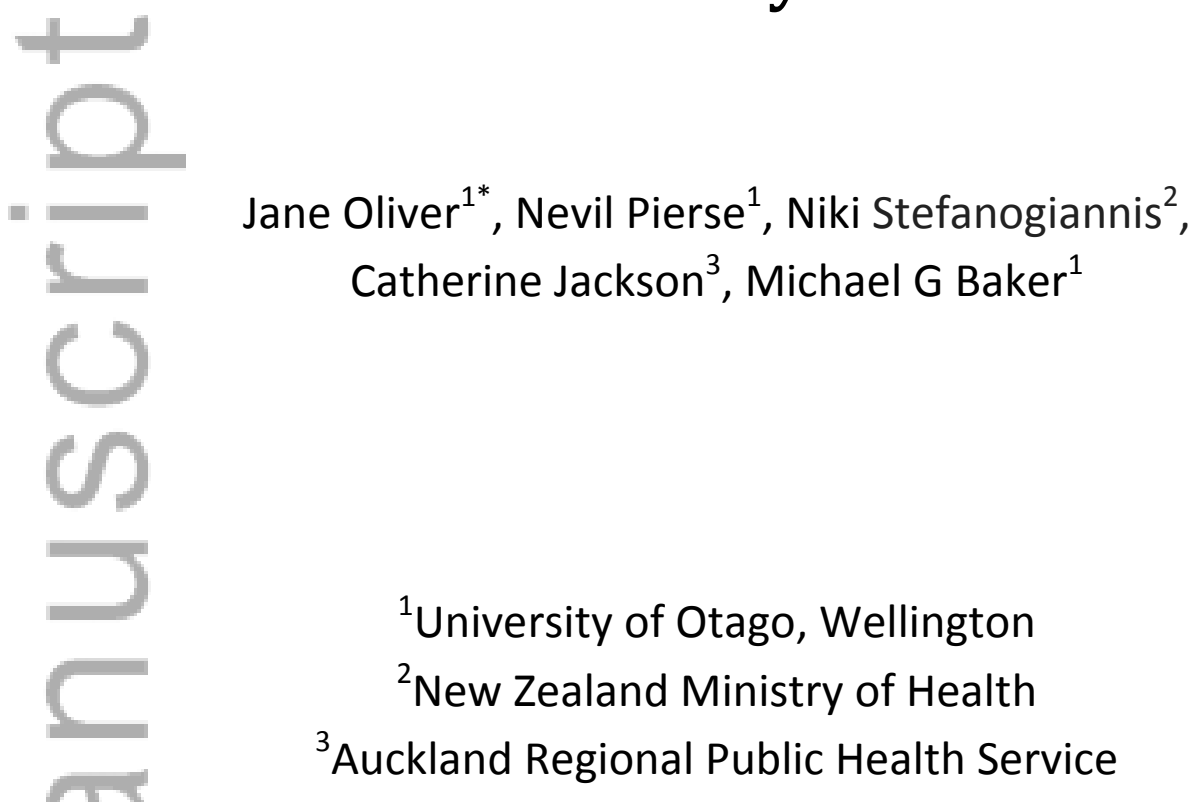

\section{Corresponding author:}

Jane Oliver

Department of Public Health, University of Otago, Wellington, New Zealand.

PO Box 7343, Wellington South 6242

Street address: 23a Mein St, Newtown

Phone +644918 6123

Mob: +64 277498880

Email: jane.rachel.oliver@otago.ac.nz

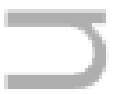

\section{Authors' email addresses:}

jane.rachel.oliver@otago.ac.nz

nevil.pierse@otago.ac.nz

Niki_Stefanogiannis@moh.govt.nz

This is the author manuscript accepted for publication and has undergone full peer review but has not been through the copyediting, typesetting, pagination and proofreading process, which may lead to differences between this version and the Version of Record. Please cite this article as doi: 
CatherineJ@adhb.govt.nz

michael.baker@otago.ac.nz

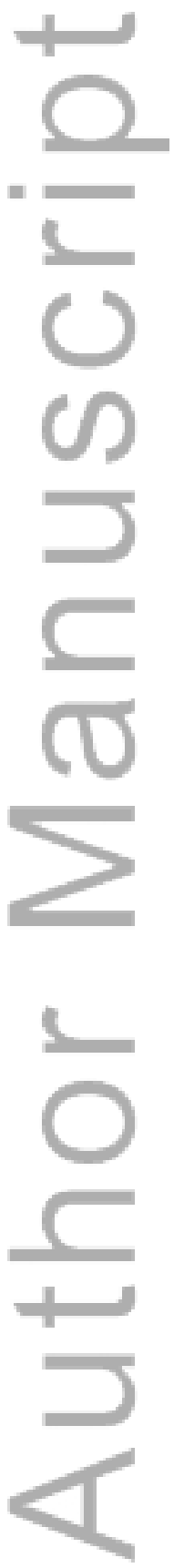

This article is protected by copyright. All rights reserved. 


\section{Abstract}

Aims

Acute rheumatic fever (ARF) is an important public health problem in low and middle income countries and in certain populations in high income countries. Indigenous Australians, and New Zealand (NZ) Māori and Pacific peoples, have incidence rates among the highest in the world. We aimed to investigate ARF cases' housing conditions and sore throat treatment to identify opportunities for improved ARF prevention in NZ.

\section{Methods}

Recently diagnosed cases and their caregivers were interviewed. Information was obtained about the cases' demographics, housing circumstances and conditions, and sore throat treatment preceding ARF.

\section{Results}

We interviewed 55 cases. Most (75\%) lived in rental housing and reported multiple measures of deprivation. Common exposures were household crowding (58\%), bed-sharing (49\%), dampness and mould $(76 \%)$, cold $(82 \%)$, and co-habiting with smokers (71\%). Experiencing sore throat in the weeks before ARF was recalled by $62 \%$, with $29 \%$ seeing a doctor or nurse and $13 \%$ of the total sample receiving antibiotics.

\section{Conclusions}

The environmental conditions reported could contribute to high GAS transmission and susceptibility to infection, thus increasing ARF risk. Sore throat treatment has important limitations as an intervention, particularly as $38 \%$ of participants did not recall sore throat preceding the diagnosis. The results support the need to improve rental housing. Interventions promoting minimum enforceable standards in social housing and private rental sectors (such as a housing warrant of fitness) could support these changes. A rigorous investigation, such as a case-control study, is needed to explore risk factors further.

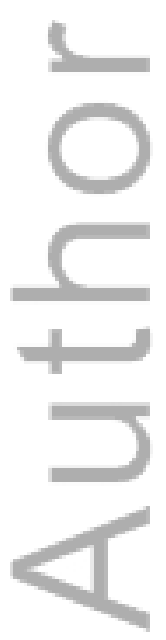

This article is protected by copyright. All rights reserved. 


\section{Introduction}

Acute rheumatic fever (ARF) is an autoimmune illness which may cause rheumatic heart disease (RHD), a serious and sometimes fatal condition. ARF occurs in $0.3-3 \%$ of people as an aberrant immune response following group A Streptococcus (GAS) infection.(1-3) Rates peak in children aged 5-14 years old. ARF is rare in nearly all high-income countries, however Māori and Pacific New Zealanders are dramatically over-represented in national incidence rates, as are Indigenous Australians.(4)

There are considerable gaps in knowledge of the aetiology and risk factors of ARF. This limits the effectiveness of disease control and prevention interventions.(5) Attempts to identify host factors have produced inconsistent results. $(6,7)$ A few case-control studies of ARF have been conducted,(8, 9) but hone of a high-quality. $(10,11)$ One study identified several factors as significantly associated with ARF, the strongest being parental unemployment.(8) Poor living conditions, including home dampness and home crowding were significant risk factors.(8) Frequent sore throat and low education level of mother were also risk factors.(8) A smaller study identified associations with ARF and low income, substandard housing, and poor nutritional status.(9) Another study observed an association with the number of children in the household.(12) Several cross-sectional studies of RHD have been carried out in developing countries,(13-17) with evidence of increased risk in low socioeconomic settings during childhood, and an association with crowding found in one study.(15) The single reported cohort study of RHD found no significant association between household crowding in childhood and RHD death however.(18) It is unknown whether secondhand smoke (SHS) exposure increases ARF risk, however smokers harbor more potential pathogens in their oral microflora, which may increase their children's risk of GAS infection.(19) A New Zealand (NZ) ecological study associated ARF with neighbourhood deprivation, household crowding, and the proportion of 5-14 year old children in the area.(20) Although based on ecological findings, it is widely thought the dramatic decline in ARF throughout Europe and North America during the last century was due to improvements in socioeconomic and housing conditions, reductions in household crowding, and increased use of antibiotics to treat streptococcal pharyngitis.(21) GAS is very infectious, so conditions (such as cold and mould) that enhance transmission, for example by reducing immune function, are certainly plausible risk factors.(23-25) Seasonality in ARF and pharyngitis is apparent in $N Z$, with rates peaking in winter. $(26,27)$

The NZ government implemented a national ARF prevention programme (RFPP) in conjunction with district health boards (DHBs). This descriptive study was contracted by the Ministry of Health (MoH) with the goal of improving the evidence base to support ARF prevention. To investigate environmental risk factors associated with ARF, we quantified cases' exposures to poor quality housing conditions, healthcare and household crowding around the time of diagnosis. Our aims were to:

1. Investigate housing tenure of ARF cases.

2. Investigate the housing conditions and household crowding exposures of ARF cases. 
3. Investigate whether ARF cases received antibiotic treatment for pharyngitis (if present) in the 2-3 weeks prior to developing ARF.

4. Identify important research questions for more detailed investigation with a case-control study.

\section{Methods}

Full ethics approval was granted by the University of Otago Ethics Committee. North Island Public Health Unit (PHU) staff contacted ARF cases notified between 1 January 2012 and 12 March 2013, or their parent/caregiver if the case was younger than 16 years old. Staff explained the study and requested consent to pass contact details on to the research team.

Participants were interviewed by a single researcher using a standard questionnaire. The questionnaire contained five sections, concerning the case's demographics, housing circumstances and conditions, household heating, and household crowding. Questions were generally selected from pre-existing survey questionnaires. Responses were tabulated and presented as counts and proportions (percentages). Stratification according to ethnicity and housing tenure was performed for certain factors. Household crowding was calculated using the Canadian National Occupancy Standard (CNOS), which describes structural crowding levels according to bedroom deficits. CNOS considers the age, relationship status and gender of the occupants. 'Structural crowding' is defined as the extra bedrooms a home requires to be free of crowding.(28) Proportions of participants exposed to crowding, dampness, cold and financial deprivation were reported according to key indicator exposures, such as electricity being cut off. Most exposures concerned the year preceding ARF diagnosis, however cold exposures concerned the winter before the diagnosis. These periods were selected in an attempt to minimise recall bias. 'Acceptable' heating methods were those not considered likely to impair respiratory health, such as electric heaters.(29)

The prioritised ethnicity classification system was used. Here respondents indicating membership of more than one ethnic group are allocated to a single ethnic group based on a prioritised order of Māori, Pacific, Asian and Other. Consequently the Other ethnic group effectively refers to nonMāori, non-Pacific, non-Asian people.(30) The New Zealand Index of Deprivation (NZDep) system is used as a measure of socioeconomic deprivation over small areas.(31) Deciles 1-2 represent people living in least deprived areas and deciles 9-10 represent those in most deprived areas.

This study did not have a control group. To indicate the distribution of exposures of interest in the source population, we used comparison statistics from the 2013 Census where possible, or survey data collected from parents of children aged 3 to 10 years in the Wellington region who were controls for a mould case-control study. We also used data on notified ARF cases for some comparisons. The test of equal or given proportions was performed to investigate whether the proportion of participants exposed to the factor of interest was significantly different from the comparison group, if it could be assumed that the proportion of exposed individuals in the comparison group was fixed (eg. census controls). Alternatively the Chi-squared test was used 
(Mould Study controls). Where a statistically significant difference was detected, the comparison statistic was highlighted in the table.

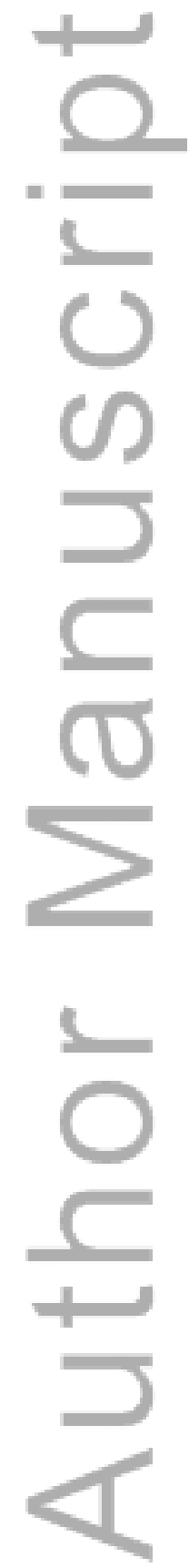

This article is protected by copyright. All rights reserved. 


\section{Results}

\section{Study population and response proportion}

In total, 160 cases with initial attacks of ARF were notified between 1 January 2012 and 12 March 2013. Contact details for 73 notified cases were received. Fifteen could not be contacted. Two interviews could not be conducted due to a language barrier. One declined to be interviewed. A total of 55 people were interviewed. The interviewer's impression was that the interview process was well-received. All participants agreed to have interview data linked with case notification data. Most interviews lasted around 5 minutes, range 4-15 minutes.

The demographic characteristics of the study participants did not differ significantly from the total ARF cases notified over the study period. Māori and Pacific peoples, children aged 5-14 years old and people living in more deprived areas were markedly over-represented in the study population compared with the general population. Participants reported significantly lower rates of home ownership at the time of diagnosis than the general population. Only $25.5 \%$ of participants lived in owner-occupied homes, compared with $64.8 \%$ of the general population. While only $3.4 \%$ of the general population lived in social housing (ie. Housing New Zealand properties provided at a subsidised rent), $34.5 \%$ of the cases did. A further $40.0 \%$ lived in the private rental sector, compared with $25.8 \%$ of the general population (Table 1 ).

Table 1: Demographic characteristics of ARF study participants compared with ARF notifications and the NZ population

\section{Crowding}

Household crowding was common, with $58.2 \%$ of participants experiencing a bedroom deficit of one or more, including $34.5 \%$ with a bedroom deficit of two or more (severe crowding). This is much higher than reported for the entire Māori and Pacific child population (in the 2013 census, $23.1 \%$ of Maori children experienced a bedroom deficit of at least one, and $42.3 \%$ of Pacific children).(32) Only six of the 19 social housing homes were not crowded. In the private rental sector, 11 of 22 homes had a bedroom deficit of one or more, as did six of 14 of owner-occupied homes. The mean number of additional bedrooms required to alleviate structural crowding was 2.1 ; range 1-6 bedrooms, interquartile range 1-3.

Thirty-eight cases (69.1\%) usually shared their bedroom with at least one other person, with on average 2.3 other people (range 1-10 others).

Twenty-seven cases $(49.1 \%)$ shared their bed. Of those cases who shared their bed, the median number of other people they shared with was 1 , (mean 1.8, range: 1-5 others). Proportions sharing their bedroom or bed were significantly higher than in the Mould Study control group (Table 2). Eight cases shared their bed with at least one adult and 19 with at least one child. 
Table 2. Prevalence of household crowding in ARF study population compared with NZ Census and Mould Study controls

\section{Financial deprivation}

We took indicators of financial deprivation to be: 1) receiving notice that a power bill had not been paid on time, 2) power cut off due to unpaid bills, 3) needing to feel cold inside to save money, 4) the household's main income being a government benefit, 5) owning a Community Services Card. A Community Services Card is available to low- and middle-income New Zealanders to help reduce healthcare costs.. The exposure period for these indicators was during the year before the ARF case was diagnosed, except for indicator 3 ) which applied during the winter preceding diagnosis.

Forty-six of 55 (83.6\%) participants experienced at least one indicator of financial deprivation. Of those in owner-occupied homes, $35.7 \%$ (5 of 14) experienced at least two indicators and $84.6 \%$ (9 of 14) had experienced at least one. Nearly all, $94.7 \%$ (18 of 19), in social housing had experienced at least two indicators, with only one not experiencing any. Of those in private rental homes, $81.8 \%$ (18 of 22) had experienced at least two indicators (and 20 experienced at least one), with only two not experiencing any.

\section{Housing conditions and indoor air quality}

Most participants (76.4\%) reported exposure to at least one of: damp walls or ceilings, mould or a musty smell in the bedrooms or living areas of their home, in the 12 months preceding the ARF diagnosis. The majority of homes $(70.9 \%)$ had at least one smoker living in them. Participants reported a significantly higher prevalence of dampness and musty smelling homes the the Mould Study controls ( $p<0.05$, Chi-squared test), but not of visible mould or mildew. The Mould Study group was not however, representative of the general population, with a considerably higher household income level, or representative of the study population, with a much higher rate of home ownership (Dr. Caroline Shorter, University of Otago, 12 February 2015, personal communication).

Most participants (81.8\%), experienced one or more indicators of exposure to cold housing, ie. needing to sleep in the same room as others to keep warm, feeling their home was too cold inside, or needing to feel cold inside to save money on heating during the winter preceding diagnosis (Table 3).

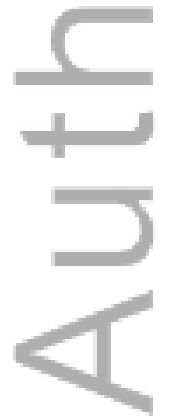

This article is protected by copyright. All rights reserved. 
Table 3. Exposure to cold housing, indoor air quality and participants' impression of house conditions in the ARF study population

A moderate proportion of participants reported difficulty paying power bills, with $32.7 \%$ having received notice that a power bill had not been paid in the 12 months preceding diagnosis, and $21.8 \%$ having power cut off (or prepaid meters running out). Of those in owner-occupied homes, $42.9 \%$ (6 of 14) reported having needed to sleep in the same room as other people to keep warm, having felt their home was too cold inside, or that they had needed feel cold inside to save money. In contrast, 90.9\% (20 of 22) of participants in private rental homes were affected by at least one of these indicators, as were all 19 participants in social housing.

The majority of participants (54.5\%) used 'acceptable' heating sources as the major way of heating their living rooms at the time of the ARF diagnosis. 'Acceptable' sources include enclosed fires, flued gas heaters, heat pumps, electric heaters, and central heating. Unflued gas heaters were the most common 'unacceptable' heating source, used by $16.4 \%$ of participants. A total of $16.4 \%$ of participants did not heat their living rooms, and $75.1 \%$ did not heat the room the case usually slept in. In the Mould Study control group only $14.7 \%$ of participants did not heat the child's bedroom (Dr. Caroline Shorter, University of Otago, 12 February 2015, personal communication).

\section{Sore throat and access to healthcare}

Almost $65 \%$ of participants $(\mathrm{N}=34)$ thought, or were certain, the case experienced a sore throat 2-3 weeks before their ARF diagnosis. Of these, 29.4\% ( $N=10)$ responded ' $Y e s^{\prime}$ ' when asked whether a doctor or a nurse had been seen about the sore throat, and $70.0 \%(\mathrm{~N}=7)$ of this group received antibiotics prior to the ARF diagnosis.

By comparison, after the RFPP gained momentum over 2013,(27) $54.3 \%(\mathrm{~N}=69)$ of ARF cases notified from 1 July 2014 to 30 June 2015 ( $N=127$ ) recalled experiencing a sore throat in the four weeks preceding diagnosis, and $60.9 \%$ (42 of 69 cases) saw a healthcare professional about it. Of these cases, 73.8\% ( $\mathrm{N}=31$ ) were prescribed antibiotics (Dr. Niki Stefanogiannis, Ministry of Health, 23 March 2016, personal communication).

This article is protected by copyright. All rights reserved. 


\section{Discussion}

This study presents the first descriptive NZ data on ARF cases' housing circumstances and environmental exposures. Despite the relatively small sample size, the findings suggest this population is exposed to multiple environmental hazards. Participants reported high levels of exposure to household crowding, financial deprivation, cold, damp homes, and living with smokers.

Cases demonstrated a clear reliance on rental housing. Almost $75 \%$ lived in rental housing, markedly more than the general population (Table 1). This result is consistent with a previous study, which found that about a third of ARF cases lived in social housing.(33) That study noted that most excess risk for the social housing population disappeared when rates were adjusted for age and ethnicity.(33) This finding illustrates the large confounding effect of ethnicity and deprivation on observed associations between ARF and housing tenure.

Household crowding was very common in our sample. Household crowding was high for Māori and Pacific children. Despite this, the NZ Asian population demonstrates nearly the same level of crowding as Māori, but is low-risk for ARF.(34) This finding suggests the association may be modified by other factors, such as the age composition of the household, bed sharing, and other features of deprivation. A strikingly high proportion of cases slept in the same bed as others which could facilitate the spread of GAS. Exposure to poor housing conditions and deprivation was widespread, particularly in the rental sector.

Approximately two-thirds of participants recalled a sore throat preceding ARF. A low proportion sought and received treatment for it. While we are unable to confirm what the prescribed antibiotic was, antimicrobial resistance is not likely to have been an issue.(35) Of cases notified in 2014-15, a considerably higher proportion who recalled a preceding sore throat sought and received treatment for it (45\%). Thus while there has been improvement, there may still be issues in access to healthcare and awareness of the need to treat sore throats, despite the considerable work of the RFPP addressing these areas. These findings could lend support to community-based primary prevention trials to assess the effectiveness of sore throat management for ARF prevention.

Around one-third of cases did not appear to experience a sore throat preceding diagnosis. This is consistent with some previous literature.(36) Consequently improving treatment of GAS pharyngitis cannot directly address the occurrence of ARF in these individuals. Improving the housing of at-risk children can theoretically reduce risk of GAS transmission and ARF, even in those who don't experience a sore throat.

This small study identified strong themes regarding possible risk factors, consistent with previous research.(10) While the study population is demographically representative of notified cases, it is unclear whether it is representative with regards to other potentially confounding exposures. We were only able to contact $20 \%$ of the notified cases, thus results may well be affected by respondent bias. Recall bias may also have impaired accuracy of the results, especially given the retrospective interview process and sometimes lengthy time delay from illness onset till the interview. Living 
conditions in preceding years may also influence ARF risk, however we did not investigate this due to additional recall bias. It is unclear how these biases may have affected our findings. Another limitation concerns the lack of a control population and appropriate comparison groups.

This study design has potential for confounding and is unable to demonstrate causal association. While the interview questions were kept brief for the participants' convenience, their limited scope reduces the ability to identify confounding. Poor housing conditions and household crowding may directly promote ARF or be markers of poverty, which increases the risk of ARF through a range of different pathways.(4) Selected indicators of poor housing and deprivation may not have been entirely accurate. It is unclear how valid the test of equal or given proportions was when investigating significant differences in exposures between participants and comparison groups, due to differences in age and ethnic distributions. Furthermore, comparison groups were selected for convenience and do not necessarily correspond appropriately to the cases. They provide a general contrast only.

A nationwide NZ case-control study is currently underway to assess the association between ARF and a wide range of specific risk factors. It uses a similar (expanded) questionnaire, refined using results from this small pilot study. It will investigate factors such as skin infection, as well as sore throat, preceding ARF to see if improved access to primary health care has greater potential as an intervention to prevent ARF. Importantly it has a carefully chosen control population to allow associations with specific risk factors to be assessed robustly.

We consider our findings could support the need to create and enhance warm, dry, non-crowded home environments, particularly for Māori and Pacific children. It appears plausible that cold, crowded, damp housing increases transmission of GAS infections. $(37,38)$ NZ Government agencies have already demonstrated capacity to deliver highly effective housing interventions to the social housing sector.(39) This housing sector could lend itself well to pilot studies aiming to improve health outcomes, before extending promising interventions more widely. Deprived groups often rely on rental housing. It is therefore important to consider approaches that raise the quality of private rental and social housing. Implementing minimum enforceable standards in these sectors may reduce the incidence of ARF and other diseases associated with poor quality housing, which exert a significant burden in deprived communities.(40)

What is already known on this topic? Acute rheumatic fever (ARF) is an important public health problem in low and middle income countries and in certain, typically indigenous, populations in high income countries. While some research has associated ARF with low socioeconomic status and poor housing, there are major gaps in knowledge of ARF risk factors. These gaps reduce the ability to design effective prevention interventions.

What this study adds: This first descriptive data on the housing circumstances and environmental exposures of ARF cases in New Zealand indicates that poor housing and deprivation are highly prevalent. Interventions promoting minimum enforceable standards for rental housing may reduce the burden of ARF and other diseases of poverty. A rigorous investigation, such as a case-control study, is needed to explore risk factors further. 


\section{REFERENCES}

1. Rammelkamp CH, Jr. Epidemiology of streptococcal infections. Harvey Lect. 1955;51:113-42.

2. Porth C. Essentials of pathophysiology: concepts of altered health states. Hagerstown, Maryland: Lippincott Williams \& Wilkins; 2007.

3. Parks T, Smeesters PR, Steer AC. Streptococcal skin infection and rheumatic heart disease. Current Opinion in Infectious Diseases. 2012;25(2):145-53.

4. Carapetis JR, Steer AC, Mulholland EK, Weber M. The global burden of group A streptococcal diseases. The Lancet Infectious Diseases. 2005;5(11):685-94.

5. Guilherme L, Kalil J. Rheumatic fever and rheumatic heart disease: cellular mechanisms leading autoimmune reactivity and disease. Journal of Clinical Immunology. 2010;30(1):17-23.

6. Engel ME, Stander R, Vogel J, Adeyemo AA, Mayosi BM. Genetic susceptibility to acute rheumatic fever: a systematic review and meta-analysis of twin studies. PLoS ONE.

2011;6(9):e25326.

7. Bryant PA, Robins-Browne R, Carapetis JR, Curtis N, Bryant PA, Robins-Browne R, et al. Some of the people, some of the time: susceptibility to acute rheumatic fever. Circulation.

2009;119(5):742-53.

8. Vlajinac H, Adanja B, Marinkovic J, Jarebinski M. Influence of socio-economic and other factors on rheumatic fever occurrence. European Journal of Epidemiology. 1991;7(6):702-4.

9. Zaman MM, Yoshiike N, Rouf MA, Haque S, Chowdhury AH, Nakayama T, et al. Association of rheumatic fever with serum albumin concentration and body iron stores in Bangladeshi children:

Case-control study. Br Med J. 1998;317(7168):1287-8.

10. New Zealand Guidelines Group. RapidE: Rheumatic Fever. A systematic review of the literature on health literacy, overcrowding and rheumatic fever. Wellington: New Zealand Guidelines Group, 2011.

11. Baker MG, McDonald A, Zhang J, Howden-Chapman P. Infectious diseases attributable to household crowding in New Zealand: A systematic review and burden of disease estimate Wellington He Kainga Oranga/Housing and Health Research Programme, University of Otago, 2013. 12. Kurahara DK, Grandinetti A, Galario J, Reddy DV, Tokuda A, Langan S, et al. Ethnic differences for developing rheumatic fever in a low-income group living in Hawaii. Ethnicity \& Disease. 2006;16(2):357-61.

13. Oli K, Porteous J. Prevalence of rheumatic heart disease among school children in Addis Ababa. East African Medical Journal. 1999;76(11):601-5.

14. Anabwani GM, Amoa AB, Muita AK. Epidemiology of rheumatic heart disease among primary school children in western Kenya. International Journal of Cardiology. 1989;23(2):249-52.

15. Ba-Saddik IA, Munibari AA, AI-Naqeeb MS, Parry CM, Hart CA, Cuevas LE, et al. Prevalence of rheumatic heart disease among school-children in Aden, Yemen. Annals of Tropical Paediatrics. 2011;31(1):37-46.

16. Dobson J, Steer AC, Colquhoun S, Kado J. Environmental factors and rheumatic heart disease in Fiji. Pediatr Cardiol. 2012;33(2):332-6.

17. Rizvi SF, Khan MA, Kundi A, Marsh DR, Samad A, Pasha O. Status of rheumatic heart disease in rural Pakistan. Heart. 2004;90(4):394-9.

18. Coggon D, Barker DJ, Inskip H, Wield G. Housing in early life and later mortality. J Epidemiol Community Health. 1993;47(5):345-8. 
19. Gordis L, Lilienfeld A, Rodriguez R. Studies in the epidemiology and preventability of rheumatic fever. II. Socio-economic factors and the incidence of acute attacks. Journal of Chronic Diseases. 1969;21(9):655-66.

20. Brook I. The impact of smoking on oral and nasopharyngeal bacterial flora. J Dent Res. 2011;90(6):704-10.

21. Jaine R, Baker M, Venugopal K, Jaine R, Baker M, Venugopal K. Acute rheumatic fever associated with household crowding in a developed country. Pediatr Infect Dis J. 2011;30(4):315-9. 22. Markowitz M. The decline of rheumatic fever: Role of medical intervention: Lewis W. Wannamaker Memorial Lecture. The Journal of Pediatrics. 1985;106(4):545-50.

23. Danchin MH, Rogers S, Kelpie L, Selvaraj G, Curtis N, Carlin JB, et al. Burden of acute sore throat and group $A$ streptococcal pharyngitis in school-aged children and their families in Australia. Pediatrics. 2007;120(5):950-7.

24. Bowie C, Pearson AL, Campbell M, Barnett R. Household crowding associated with childhood otitis media hospitalisations in New Zealand. Australian and New Zealand Journal of Public Health. 2014;38(3):211-5.

25. Gracey M, Williams P, Houston S. Environmental health conditions in remote and rural aboriginal communities in western Australia. Australian and New Zealand Journal of Public Health. 1997;21(5):511-8.

26. Jaine R, Baker M, Venugopal K. Epidemiology of acute rheumatic fever in New Zealand 19962005. Journal of Paediatrics and Child Health. 2008;44(10):564-71.

27. Jack S WD, Galloway Y, Pierse N, Milne R, Mackereth G, Zhang J, Oliver J, Baker MG,. Interim Evaluation of the Sore Throat Component of the Rheumatic Fever Prevention Programme Quantitative Findings. The Institute of Environmental Science and Research Ltd. Porirua, New Zealand: 2015.

28. Canadian Ministry of Housing Corporation. Core housing need in Canada. Ottawa: Canadian Government Print. 1991.

29. Free S, Howden-Chapman P, Pierse N, Viggers H, Housing H, Health Study Research T. More effective home heating reduces school absences for children with asthma. J Epidemiol Community Health. 2010;64(5):379-86.

30. Ministry of Health. Ethnicity Data Protocols for the Health and Disability Sector. Wellington: 2004.

31. Salmond CE, Crampton P. Development of New Zealand's deprivation index (NZDep) and its uptake as a national policy tool. Can J Public Health. 2012;103(8 Suppl 2):S7-11.

32. Ministry of Health. Analysis of Household Crowding based on Census 2013 data. Wellington: Ministry of Health. 2014.

33. Baker MG, Zhang J, Howden-Chapman P. Health status of Housing New Zealand applicants and tenants: Key indicators for 2004-2010. Wellington: He Kainga Oranga / Housing and Health Research Programme, University of Otago, Wellington, 2012.

34. Baker M, Goodyear R, Telfar Barnard L, Howden-Chapman P. The distribution of household crowding in New Zealand: An analysis based on 1991 to 2006 Census data. Wellington Wellington: He Kainga Oranga/ Housing and Health Research Programme, University of Otago; 2012 [Available from: http://www.healthyhousing.org.nz/wp-content/uploads/2010/01/HH-Crowding-in-NZ-25May-2013.pdf.

35. Heart Foundation of New Zealand. New Zealand Guidelines for Rheumatic Fever: Diagnosis, Management and Secondary Prevention of Acute Rheumatic Fever and Rheumatic Heart Disease: 2014 Update. 2014. 
36. Noonan S, Zurynski YA, Currie BJ, McDonald M, Wheaton G, Nissen M, et al. A national prospective surveillance study of acute rheumatic fever in Australian children. Pediatr Infect Dis J. 2013;32(1):e26-32.

37. Pierse N., Arnold R., Keall M., Howden-Chapman P., Crane J., Cunningham M. Modelling the effects of low indoor temperatures on the lung function of children with asthma. J Epidemiol Community Health. 2013;67(11):918-25.

38. Gray GC, Callahan JD, Hawksworth AW, Fisher CA, Gaydos JC. Respiratory diseases among US military personnel: Countering emerging threats. Emerg Infect Dis. 1999;5(3):379-87.

39. Jackson G, Thornley S, Woolston J, Papa D, Bernacchi A, Moore T. Reduced acute hospitalisation with the healthy housing programme. Journal of Epidemiol Community Health. 2011;65(7):588-93.

40. Anderson P, Craig E, Jackson G, Jackson C. Developing a tool to monitor potentially avoidable and ambulatory care sensitive hospitalisations in New Zealand children. New Zealand Medical Journal. 2012;125(1366):25-37.

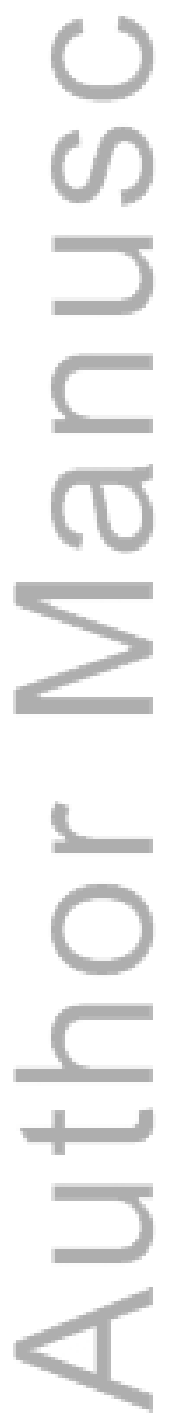

This article is protected by copyright. All rights reserved. 
Table 1: Demographic characteristics of ARF study participants compared with ARF notifications and the NZ population

\begin{tabular}{|c|c|c|c|c|}
\hline $\begin{array}{l}\text { Demographic } \\
\text { factor }\end{array}$ & $\begin{array}{l}\text { No. } \\
\text { Participants } \\
(\mathrm{N}=55)\end{array}$ & $\begin{array}{l}\text { Proportion } \\
\text { participants } \\
\text { (\% study } \\
\text { total) }\end{array}$ & $\begin{array}{l}\text { Total } \\
\text { notifications } \\
(\mathrm{N}=160)\end{array}$ & $\begin{array}{l}2013 \text { Census } \\
\text { Population } \\
\text { (\% total } \\
\text { population) }\end{array}$ \\
\hline \multicolumn{5}{|l|}{ Age group } \\
\hline$<5 \quad 1$ & 0 & 0.0 & 0 & 14.0 \\
\hline $5-14$ & 44 & 80.0 & 117 & 5.6 \\
\hline $15-30$ & 10 & 20.0 & 41 & 8.5 \\
\hline$\geq 31$ & 1 & 1.8 & 2 & 67.7 \\
\hline Unknown & 0 & 0.0 & 0.0 & 0.1 \\
\hline \multicolumn{5}{|l|}{ Sex } \\
\hline Female & 29 & 52.7 & 94 & 51.2 \\
\hline Male & 26 & 47.3 & 66 & 48.8 \\
\hline \multicolumn{5}{|l|}{ Prioritised } \\
\hline \multicolumn{5}{|l|}{ Ethnicity } \\
\hline Māori & 35 & 63.6 & 85 & 13.5 \\
\hline Pacific & 19 & 34.5 & 69 & 6.7 \\
\hline Asian & 0 & 0.0 & 2 & 10.6 \\
\hline Other & 1 & 1.8 & 3 & 69.3 \\
\hline Unknown & 0 & 0 & 1 & 0.0 \\
\hline \multicolumn{5}{|l|}{$\begin{array}{l}\text { NZ Deprivation } \\
\text { Index } 2013\end{array}$} \\
\hline $1-2$ & 2 & 3.6 & 5 & 20.5 \\
\hline $3-4$ & 1 & 7.8 & 8 & 20.1 \\
\hline $5-6$ & 3 & 5.5 & 10 & 19.8 \\
\hline $7-8$ & 11 & 20.0 & 26 & 19.6 \\
\hline $9-10$ & 34 & 61.8 & 109 & 19.8 \\
\hline Unknown & 4 & 7.3 & 2 & 0.1 \\
\hline \multicolumn{5}{|l|}{ Housing Tenure } \\
\hline Owner-occupied & 14 & 25.5 & - & 64.8 \\
\hline Private rental & 22 & 40.0 & - & 25.8 \\
\hline Social housing & 19 & 34.5 & - & 3.4 \\
\hline Other & 0 & 0.0 & - & 6.0 \\
\hline
\end{tabular}

NB: Bold numbering indicates exposure levels are significantly different between cases and the comparison group ( $p<0.05$, Chi-squared tests/test of equal of given proportions). 
Table 2. Prevalence of household crowding in ARF study population compared with NZ Census and Mould Study controls

\begin{tabular}{|c|c|c|c|}
\hline \multirow[t]{2}{*}{ Indicators of household crowding } & \multicolumn{2}{|c|}{$\begin{array}{c}\text { Total sample } \\
\mathrm{N}=55 \text { participants }\end{array}$} & \multirow{2}{*}{$\begin{array}{c}\text { Comparison source: } \\
\text { NZ Census 2006/Mould } \\
\text { Study controls } \\
\%\end{array}$} \\
\hline & $\mathbf{n}$ & $\%$ & \\
\hline Household with 1+ bedroom deficit & 32 & 54.5 & $\underline{10.4}$ \\
\hline Household with $2+$ bedroom deficit & 19 & 34.5 & $\underline{3.5}$ \\
\hline No bedroom deficit & 23 & 45.5 & $\overline{89.6}$ \\
\hline Unsure & 0 & 0.0 & $\underline{\underline{0.0}}$ \\
\hline \multicolumn{4}{|l|}{$\begin{array}{l}\text { Households with } 1+\text { bedroom deficit by } \\
\text { prioritised ethnicity }\end{array}$} \\
\hline Māori & 16 & 45.7 & $\underline{20.0}$ \\
\hline Pacific & 14 & 73.7 & $\overline{39.8}$ \\
\hline European/Other & 0 & 0.0 & $\underline{4.3}$ \\
\hline \multicolumn{4}{|l|}{ Cases sleeping in same bedroom as other people } \\
\hline Case only & 17 & 30.9 & 68.0 \\
\hline At least 1 other person & 38 & 69.1 & 32.0 \\
\hline 1 other person & 18 & 32.7 & - \\
\hline 2 other people & 9 & 16.4 & - \\
\hline At least 3 other people & 11 & 20.0 & - \\
\hline Unsure & 0 & 0.0 & 0.0 \\
\hline \multicolumn{4}{|l|}{$\begin{array}{l}\text { Cases sleeping in } \\
\text { same bed as other people }\end{array}$} \\
\hline Case only & 28 & 50.9 & 80.0 \\
\hline At least 1 other person & 27 & 49.1 & 19.3 \\
\hline 1 other person & 18 & 32.7 & - \\
\hline 2 other people & 2 & 3.6 & - \\
\hline At least 3 other people & 7 & 12.7 & - \\
\hline Unsure & 0 & 0.0 & 0.7 \\
\hline
\end{tabular}

NB: Bold numbering indicates exposure levels are significantly different between cases and the comparison group ( $p<0.05$, Chi-squared tests/test of equal of given proportions).

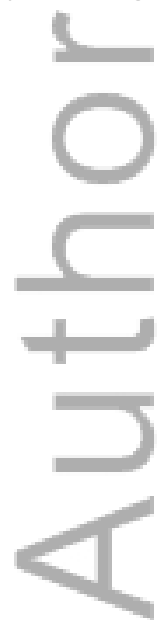

This article is protected by copyright. All rights reserved. 
Table 3. Exposure to cold housing, indoor air quality and participants' impression of house conditions in the ARF study population

\begin{tabular}{|c|c|c|}
\hline \multirow[t]{2}{*}{ Key housing exposure } & \multicolumn{2}{|c|}{$\begin{array}{c}\text { Total sample } \\
\text { ( } \mathrm{N}=55 \text { participants) }\end{array}$} \\
\hline & $\mathbf{n}$ & $\%$ \\
\hline \multicolumn{3}{|c|}{ How often was dampness noticed on walls/ceilings } \\
\hline Yes - always & 20 & 36.4 \\
\hline Yes - often & 6 & 10.9 \\
\hline Yes - sometimes & 6 & 10.9 \\
\hline No $\quad$ & 22 & 40.0 \\
\hline Unsure & 1 & 1.8 \\
\hline \multicolumn{3}{|c|}{ How often did house smell mouldy/musty } \\
\hline Yes - always & 16 & 29.1 \\
\hline Yes - often & 9 & 16.4 \\
\hline Yes - sometimes & 8 & 14.5 \\
\hline No $(-)$ & 20 & 36.4 \\
\hline Unsure & 2 & 3.6 \\
\hline \multicolumn{3}{|c|}{ Frequency of mould/mildew } \\
\hline Yes - always & 18 & 32.7 \\
\hline Yes - often & 13 & 23.6 \\
\hline Yes - sometimes & 7 & 12.7 \\
\hline Never & 25 & 45.5 \\
\hline Unsure & 2 & 3.6 \\
\hline \multicolumn{3}{|c|}{ Was the house colder than preferred? } \\
\hline Yes - always & 27 & 49.1 \\
\hline Yes - often & 12 & 21.8 \\
\hline Yes - sometimes & 6 & 10.9 \\
\hline Never & 8 & 14.5 \\
\hline Unsure & 2 & 3.6 \\
\hline \multicolumn{3}{|c|}{ Did the participant feel cold inside to save money on power? } \\
\hline Yes-always & 27 & 49.1 \\
\hline Yes - often & 12 & 21.8 \\
\hline Yes - sometimes & 6 & 10.9 \\
\hline Never & 8 & 14.5 \\
\hline Unsure & 2 & 3.6 \\
\hline \multicolumn{3}{|c|}{ Did case need to sleep in same room as others just to keep warm? } \\
\hline Yes - always & 24 & 43.6 \\
\hline Yes - often & 2 & 3.6 \\
\hline Yes-sometimes & 5 & 9.1 \\
\hline Never & 24 & 43.6 \\
\hline Unsure & 0 & 0.0 \\
\hline \multicolumn{3}{|c|}{ Acceptable heating methods in living room used } \\
\hline Yes & 30 & 54.5 \\
\hline No & 25 & 45.5 \\
\hline Unsure & 0 & 0.0 \\
\hline \multicolumn{3}{|l|}{$\geq 1$ Smoker in household } \\
\hline Yes & 39 & 70.9 \\
\hline No & 16 & 29.1 \\
\hline Unsure & 0 & 0.0 \\
\hline
\end{tabular}

This article is protected by copyright. All rights reserved. 


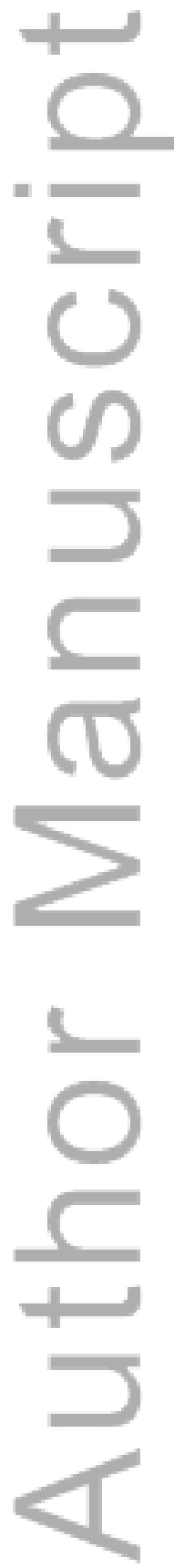

This article is protected by copyright. All rights reserved. 


\section{University Library}

\section{- M M N E R VA A gateway to Melbourne's research publications}

Minerva Access is the Institutional Repository of The University of Melbourne

Author/s:

Oliver, JR;Pierse, N;Stefanogiannis, N;Jackson, C;Baker, MG

Title:

Acute rheumatic fever and exposure to poor housing conditions in New Zealand: A descriptive study.

Date:

2017-04

Citation:

Oliver, J. R., Pierse, N., Stefanogiannis, N., Jackson, C. \& Baker, M. G. (2017). Acute rheumatic fever and exposure to poor housing conditions in New Zealand: A descriptive study. . J Paediatr Child Health, 53 (4), pp.358-364. https://doi.org/10.1111/jpc.13421.

Persistent Link:

http://hdl.handle.net/11343/292303 